\title{
PARADIGM-HF sonrası yayınlanan klinik çalışmalar: TRANSITION, PIONEER HF, EVALUATE-HF, PROVE-HF
}

\author{
Dr. Mehmet Ali Astarcıoğlu
}

Kütahya Sağlık Bilimleri Üniversitesi Tıp Fakültesi, Kardiyoloji Anabilim Dalı, Kütahya

\begin{abstract}
"PIONEER-HF ve TRANSITION çalışmalarından gelen veriler, dekompanse DEF-KY tanisı ile yatırılan hastalarda stabilizasyonu takiben ARNI'nin hastanede başlatılmasını ve ilk seçenek olarak kullanımını desteklemektedir."
\end{abstract}

2014 yılında New England Tip Dergisi'nde yayınlanan PARADIGM-HF çalışması hafif-orta kronik DEF-KY hastalarında ARNI tedavisinin enalapril'e göre mortalite ve hastaneye yatıştan oluşan birincil son noktalarda üstünlügüüü göstermiş, bu tedavinin güvenli ve uygulanabilir olduğunu ortaya koymuştur. ${ }^{[1]}$ Ancak hastaneye yatan akut dekompanse kalp yetmezliği hastaları PARADIGM-HF çalışmasından ç1karıldı $\breve{1}$ için bu tür hastalarda ilaca başlanması ile ilgili veri bulunmamaktaydı. Bu hasta grubunda ilacin güvenirlilik ve tolere edilebilirliğini değerlendirmek amacıyla dizayn edilen açık etiketli randomize bir çalışma olan TRANSITION çalışmasının on haftalık sonuçları 2019 yılında yayınland. ${ }^{[2]}$ Akut dekompanse kalp yetersizliği (KY) ile hastaneye yatırılan 1000 'den fazla DEF-KY hastası iki gruba ayrılmışlar, bunlardan ilk gruba taburculuk öncesi (hemodinamik stabilizasyondan $\geq 24$ saat sonra) ARNI tedavisi başlanmış, 10 haftalık bir gözlem süresini tamamlamıştır. İkinci gruba taburculuk sonrası (taburcu olduktan sonraki ilk 14 gün içinde) ARNI tedavisi başlanmış, yine ilk günlerden itibaren on hafta boyunca yakından izlenmişlerdir (Tablo 1).

Çalışmanın birincil sonlanım noktası, 10. haftada hedef doz olan $200 \mathrm{mg}$ sakubitril/valsartan dozuna ulaşılması olarak belirlenmiştir. İkincil sonlanım noktası ise değişik ilaç dozlarına tolerasyonun değerlendirilmesi olarak tanımlanmıştır. On haftalık takipte taburculuk öncesi grupta hastaların yüzde 45'inde hedef doza ulaşılırken, taburculuk sonras1 ARNI tedavisi başlananların yüzde 50'sinde 200 mg hedef dozuna ulaşılmıştır $(\mathrm{p}=0.092)$. Hedef doza ulaşmayı öngördüren faktörler yaşın $<65$ yıl olması,
eGFR $\geq 60 \mathrm{~mL} /$ dak $/ 1.73 \mathrm{~m}^{2}$ üzerinde olması, sistolik kan basıncinın $\geq 120 \mathrm{mmHg}$ olması, daha önceden KY nedeniyle yatıs hikayesi, AF tanısı ve hipertansiyon öyküsü bulunmaması ve tedaviye günde $2 \mathrm{kez}$ $100 \mathrm{mg}$ dozu ile başlanması olarak belirlenmiştir. Hastaların yüzde 85 'i sakubitril/valsartan kombinasyonunun farklı dozlarından birini en az 2 hafta tolere etmiş, onuncu haftaya kadar da kullanmıştır. Her iki koldaki hastalar ilacı iyi tolere etmiş, yan etki sıklığı iki tedavi grubunda benzer saptanmıştır. Bu çalışmada dikkat çeken noktalardan bir tanesi de hastaların yüzde 24'ünün daha önceden ACEi/ARB almayanlar arasından seçilmesidir.

TRANSITION çalışması, akut dekompanse KY ile yatırılan hastalarda sakubitril/valsartan tedavisinin taburculuk öncesi başlanmasının güvenli ve uygulanabilir olduğunu gösterdi.

KY kronik bir hastalık olduğundan, hastaların büyük bir kısmı klinik durumlarının kötüleşmesi nedeniyle hastaneye yatmak zorunda kalmaktadır. Beş yıl boyunca takip edilen bir KY hastasının bu süre zarfında en az bir kez hastaneye yatma oranı yüzde 83 'e karşılık gelse de, etkilenen hastalarda kısa dönemli yeniden hastaneye yatış ve ölüm oranları kabul edilemez düzeyde yüksek kalmaktadır. ${ }^{[3]}$ Akut KY tedavisi yaklaşık yarım yüzyıldır çok değişmedi; bu sebeple PIONEER-HF çalışması, bu konuya 1şık tutmak ve böylece bu hasta grubunda karşılanmamış büyük bir ihtiyacı karşılamak için gerçekleştirildi. ${ }^{[4]}$

PIONEER-HF çalışmasında, akut KY ile hastaneye yatan DEF-KY hastalarında sakubitril/valsartan ile enalapril karşılaştırılmıştır. Çalışmaya yeni başlangıçlı (yaklaşık üçte biri) veya kötüleşen kronik KY (yaklaşık üçte ikisi) nedeniyle hastaneye yatırılan akut DEF-KY hastaları (EF $\leq \% 40$ ve NTproBNP $\geq 1600 \mathrm{pg} / \mathrm{mL}$ veya $\mathrm{BNP} \geq 400 \mathrm{pg} / \mathrm{mL}$ ) dahil edilmiştir. ${ }^{[3]}$ Çalışmaya alınan 881 hasta stabilize edildikten sonra rastgele olarak sakubitril/valsartan 
Tablo 1. TRANSITION, PIONEER HF, EVALUATE-HF, PROVE-HF çalışmalarının özellikleri ve birincil sonlanımları

\begin{tabular}{|c|c|c|c|c|}
\hline & TRANSITION & PIONEER-HF & PROVE-HF & EVALUATE-HF \\
\hline Hasta özellikleri & $\begin{array}{c}\text { Akut KY } \\
(\mathrm{EF} \leq \% 40, \\
\text { Sistolik KB } \\
\geq 100 \mathrm{mmHg})\end{array}$ & $\begin{array}{c}\text { Akut KY } \\
\text { (EF } \leq \% 40, \text { BNP } \geq 400 \\
\text { veya NT-proBNP } \\
\geq 1600 \mathrm{pg} / \mathrm{mL} \text { ) }\end{array}$ & Kronik KY & Kronik KY \\
\hline Hasta sayıSı & 1002 & 881 & 794 & 464 \\
\hline Ortalama yaş & 66.8 & 61.1 & 65.1 & 67.3 \\
\hline Fonksiyonel sınıf & II-IV & IIIIV & II-IV & $|-| I \mid$ \\
\hline Çalışma süresi & 10 hafta & 8 hafta & 12 ay & 12 hafta \\
\hline Birincil sonlanım & $\begin{array}{l}\text { 10. haftada hedef } \\
\text { doz olan } 200 \mathrm{mg} \\
\text { sakubitril/valsartan } \\
\text { dozuna ulaşıması }\end{array}$ & $\begin{array}{l}\text { NT-proBNP düzeyi } \\
\text { ortalamasının } \\
\text { başlangıca } \\
\text { göre değişimi }\end{array}$ & $\begin{array}{c}\text { NT-proBNP'deki } \\
\text { değişikliklerin } \\
\text { kardiyak } \\
\text { hacim ve fonksiyon } \\
\text { ölçümlerindeki } \\
\text { değişikliklerle ilişkisi }\end{array}$ & $\begin{array}{c}\text { Aortik } \\
\text { empedansta (Zc) } \\
\text { başlangıçtan } \\
\text { 12. haftaya } \\
\text { kadar olan } \\
\text { değişiklik }\end{array}$ \\
\hline Sonuç/yorum & $\begin{array}{c}\text { Akut dekompanse } \\
\text { KY ile yatırılan } \\
\text { hastalarda } \\
\text { sakubitril/valsartan } \\
\text { tedavisinin taburculuk } \\
\text { öncesi başlanması } \\
\text { güvenli ve uygulanabilir }\end{array}$ & $\begin{array}{l}\text { Akut KY hastalarında } \\
\text { başlanan ARNI ile } \\
\text { NT-proBNP'de kısa sürede } \\
\text { azalma sağlandı ve } \\
\text { biyobelirteçlerdeki } \\
\text { bu azalma klinik } \\
\text { sonlanımlara da } \\
\text { (eksploratori sonuçlar) } \\
\text { yansımıştır }\end{array}$ & $\begin{array}{l}\text { Biyobelirteçteki } \\
\text { iyileşme ile } \\
\text { kardiyak yeniden } \\
\text { şekillenmenin } \\
\text { tersine döndüğünü } \\
\text { gösteren pozitif } \\
\text { değişiklikler } \\
\text { arasındaki ilişki } \\
\text { gösterilmiştir }\end{array}$ & $\begin{array}{c}\text { ARNI ve } \\
\text { Enalapril'in aort } \\
\text { empedansındaki } \\
\text { vasküler sertliğin } \\
\text { ölçüsü) değişimi } \\
\text { iyileştirmediği } \\
\text { gösterilmiştir }\end{array}$ \\
\hline
\end{tabular}

( $n=440)$ veya enalapril $(n=441)$ kollarına ayrılmışlar, ortalama 8 haftalık gözlem süresini tamamlamışlardır (Tablo 1).

Hastalar hastaneye yattıktan ortalama 68 saat sonra çalışmaya alınmıştır. Birincil etkinlik sonlanımı, 4. ve 8. haftadaki NT-proBNP düzeyi ortalamasının başlangıca göre değişimidir. Güvenlik sonlanım noktaları ise böbrek fonksiyonlarında bozulma, hiperkalemi, semptomatik hipotansiyon ve anjiyoödemdir.

ARNI kolunda NT-proBNP düzeyinin 4. ve 8.haftadaki ortalamasının başlangıç değerine göre değişimi enalapril grubuna göre anlamlı farklılık göstermiş, ARNI kolunda NT-proBNP'de düşme daha çok meydana gelmiştir (yüzde 47'ye karşın yüzde 25, \%95 CI: $0.63,0.81 ; \mathrm{p}<0.0001)$. Sakubitril/valsartan ile enalapril arasındaki NT-proBNP farkı ilk haftadan itibaren ortaya çıkmıştır. ARNI tedavisinin enalapril'e olan üstünlügüu alt gruplarda da devam etti; önceden KY öyküsü olan veya olmayanlarda ve önceden ACEi/ARB kullanan veya kullanmayanlarda ARNI enalapril'e üstün bulundu. Böbrek fonksiyonlarında kötüleşme, hiperkalemi, semptomatik hipotansiyon ve anjiyoödem gibi güvenlik sonlanım noktaları iki grup arasında benzerdir.

Bu çalışmanın dikkat çekici bir özelliği de randomize edilen hastalardan yüzde 34'ünde önceden KY öyküsü bulunmazken, yüzde 52'si ACEi/ARB kullanmayan hastalard1.

Sonuç olarak akut KY hastalarında başlanan ARNI ile NT-proBNP'de kısa sürede azalma sağlandı ve biyobelirteçlerdeki bu azalma klinik sonlanımlara da (eksploratori sonuçlar) yansımıştır. Çalışmanın önceden belirlenmiş bir analizinde, ARNI grubunda 41 hastada (yüzde 9.3) ve enalapril grubunda 74 hastada (yüzde 16.8) ölüm, KY sebebiyle hastaneye yatış, sol ventrikül destek cihaz ihtiyacı ya da nakil için listeye girmeden oluşan birleşik sonlanım noktalarında anlamlı farklılık görülmüş, ARNI grubunda bulunan hastalarda bu olaylar daha az meydana gelmiştir (HR 0.54, \%95 CI 0.37-0.79; p=0.001). Esas fayda ARNI 
ile tedavi edilen hastalarda ölümdeki numerik ve yeniden hastaneye yatıştaki istatiksel anlamlı azalmalar nedeniyle olmuştur. 8 haftalık takipte böyle bir klinik olayı önlemek için tedavi edilmesi gereken hasta sayıs1 (NNT oranı) 13'tür.

Akut KY ile hastaneye başvuran hastalarda sakubitril/valsartan ile enalapril'in karşılaştırıldığ PIONEER-HF çalışmasının 4 haftalık açık etiketli uzatmasının sonuçları ise 2019 yılında Amerikan Kalp Derneği Kongresi'nde açıklandı. Çalışmanın çift-kör başlangıç kısmında akut KY ile hastaneye yatırılan DEF-KY hastaları ilk 8 hafta boyunca ARNI veya enalapril'e randomize edilmişlerdi. Sonrasında her iki grup hastaya da açık etiketli olarak ARNI verildi.

Amaç; akut KY ile hastaneye yatırılan DEF-KY hastalarında enalapril'den ARNI'ye değişim yapılmasının NT-proBNP üzerinde değişikliklerinin belirlenmesi, yeniden hastaneye yatışı da içeren klinik olayların 12 haftalık periyotta iki grupta karşılaştırilmasiydi.

Çalışmaya alınan hastaların yüzde 56.8'i 97/103 mg dozunda ARNI kullanmaktaydı. Güvenlik sonlanım noktaları değerlendirildiğinde gruplar arasında anlamlı fark izlenmedi. 4 haftalık uzatma periyodunda NT-proBNP'nin her iki grupta düştügüü, hastanede ARNI başlanan ve devam edilen grupta düşüşün daha belirgin olduğu gözlendi. Hastanede enalapril başlanıp sonrasında ARNI'ye dönülen grupta da belirgin NT-proBNP düşüşü izlendi.

Bunun ötesinde çalışmanın çift kör fazında 8. haftada belgelenen iki çalışma kolu arasındaki klinik olay farkı, enalapril grubunun açık etiketli sakubitril/ valsartan'a geçmesinden sonraki 4 hafta içinde de önemli ölçüde değişmedi. Takip eden 4 haftalık uzatma fazı sırasında ölüm, KY sebebiyle hastaneye yatış, sol ventrikül destek cihaz ihtiyacı ya da nakil için listeye girmeden oluşan ciddi klinik birleşik son noktalar sürekli sakubitril/valsartan grubunda yüzde 33 daha düşüktü. Mutlak risk azalması yüzde 5.6 idi ve klinik olayları önlemek için tedavi edilmesi gereken hasta sayısı (NNT oranı) 18 olarak saptandı.

TRANSITION çalışmasından sonra PIONEERHF çalışması verileri de ARNI'nin akut KY hastalarında önceden ACEi/ARB kullanım ve KY öyküsü olup olmadığına bakılmaksızın hastaneden çıkmadan önce güvenle başlanabileceğini desteklemektedir. Özellikle akut KY hastaları taburcu olmadan önce ilaç değişimlerine ve titrasyona daha açık olmaktadır. Bu dönem klinisyenler için hastalığın seyrini değiştirecek yeni ilaçları başlamaları için de önemli bir fırsat oluşturmaktadır.

"PROVE-HF ve EVALUATE-HF çalışmaları, DEF-KY'li hastalarda ARNI'nin kalpteki yeniden şekillenmeyi tersine çevirebileceğine ve klinik sonuçlarda iyileşmeye yol açabileceğine dair ilk kanıtları ortaya koyan çalışmalardır."

PROVE-HF ve EVALUATE-HF çalışmalarından gelen kardiyak ve vasküler yeniden şekillenme verileri, 6 ay ve bir yıllık takiplerde kardiyak yapı ve fonksiyonlarda önemli iyileşmeler olduğunu göstermektedir. ${ }^{[5,6]}$

PROVE-HF çalışmasında sakubitril/valsartan'ın kardiyak yeniden şekillenme üzerindeki etkisi araştırılmıştır. Tek kollu, çok merkezli, açık etiketli faz IV çalışmasına araştırmacılar, NYHA sınıf II-IV, DEF-KY'si bulunan 794 hastayı dahil etmişler, 52 haftalık bir gözlem süresini tamamlamışlardır. Çalışmanın birincil sonlanım noktası, 12. ayda ARNI ile tedavi edilen DEF-KY hastalarında NT-proBNP'deki değişikliklerin kardiyak hacim ve fonksiyon ölçümlerindeki değişikliklerle ilişkisini belirlemekti (Tablo 1). Sonuçlar klinik ve istatistiksel olarak anlamlı bir şekilde NT-proBNP'de başlangıçtan 14. güne kadar yüzde 30'luk bir azalma gösterdi (NT-proBNP bazalde $816 \mathrm{pg} / \mathrm{mL}$ idi). Bu azalma 12 ay boyunca devam etti ve sonuçta yüzde 37'lik bir azalma gözlendi (12. ayda NT-proBNP düzeyi $455 \mathrm{pg} / \mathrm{mL}$ idi). Tüm ekokardiyografik parametrelerde (SVEF, SAVi, SVEDVi, SVESVi ve E/e') onikinci ayda klinik ve istatistiksel olarak anlamlı iyileşmeler gözlenmiştir. SVEF ortalama yüzde 28.2 'den yüzde 37.8 'e (fark yüzde 9.4 $[\% 8.8,9.9] ; \mathrm{p}<0.001)$ yükselirken SVEDVi ortalama 86.93 'ten $74.15 \mathrm{~mL} / \mathrm{m}^{2}$ 'ye (fark, -12.25 [-12.92, -11.58]; $\mathrm{p}<0.001$ ) ve SVESVi ortalama 61.68 'den $45.46 \mathrm{~mL} / \mathrm{m}^{2}$ ye düştü (fark, -15.29 [-16.03, -14.55]; $\mathrm{p}<0.001)$. SAVi ve E/e' oranı da önemli ölçüde azaldı.

NT-proBNP konsantrasyonundaki değişiklik ile yapısal kardiyak ölçümlerdeki değişiklikler arasında başlangıçtan altıncı aya kadar anlamlı bir ilişki bulunmuştur ve ilişkinin gücü birinci yılda görülenden daha azdır. Tüm ekokardiyografik ölçümlerdeki iyileşme altıncı ayda belirgindi, ancak birinci yılda daha belirgindi. Sonuç olarak, bu çalışma biyobelirteçteki iyileşme ile kardiyak yeniden şekillenmenin tersine döndüğünü gösteren pozitif değişiklikler arasındaki ilişkiyi göstermiştir.

Dört yüz altmış dört hasta prospektif, randomize, çok merkezli, çift kör, paralel grup, aktif kontrollü, 12 haftalık EVALUATE-HF faz IV çalışmasında saku- 
bitril/valsartan ve enalapril kollarına randomize edildi. ARNI'nin vasküler yeniden şekillenme ve kalbin mekanik etkinliğinin bir ölçüsü olan ventriküler-vasküler eşleşme üzerindeki etkisi incelenmiştir (Tablo 1). Birincil sonlanım noktası, merkezi aort sertliğinin bir ölçüsü olan aortik empedansta (Zc) başlangiçtan 12. haftaya kadar olan değişiklikti. Onikinci haftada ARNI ve enalapril arasında istatistiksel olarak anlamlı bir fark görülmemiştir (-2.9'a karşın -0.7 dyne$\mathrm{sec} / \mathrm{cm}^{5}$ ). İkincil sonlanım nokatalarına bakıldığında ARNI, 12. haftada enalapril'e karşı çeşitli yapısal ve fonksiyonel ekokardiyografik parametreleri (SAVi, SVEDVi, SVESVi ve E/e') iyileştirmiştir.

Bu sonuçlar, ARNI'nin enalapril ile karşılaştırıld1ğında aort empedansında (vasküler sertliğin ölçüsü) ilave bir düzelme sağlamadığını desteklemektedir. Çalışma süresinin nispeten kısa olması ve daha önce kullanılan RAAS blokerlerinin aortik empedans da bir dereceye kadar zaten düzelme sağlamış olması bu sonuca katkıda bulunmuş olabilir. Bununla birlikte, PROVE-HF' deki bulgularla tutarlı olarak, ARNI'nin enalapril ile karşılaştırıldığında sol ventrikül yapısını ve fonksiyonlarını iyileştirdiği gösterilmiştir. Her iki çalışmada da güvenlik ve tolere edilebilirlik daha önce bildirilen çalışmalarla benzer bulunmuştur.

Kardiyak yeniden şekillenme, kalbin vücuda kan pompalama yeteneğini bozar ve kötü prognoza neden olur. Bu iki çalışmanın sonuçları ARNI'nin sadece
DEF-KY'deki klinik sonuçların prognozu ile ilişkili olduğu gösterilen bir biyobelirteçi (NTproBNP) olumlu etkilemekle kalmayıp, aynı zamanda bu hastalıkta ortaya çıkan kardiyak yeniden şekillenme olarak bilinen yapısal ve fonksiyonel değişikliklerde de önemli bir iyileşme ile ilişkili olduğunu göstermektedir. İlk kez, ARNI ile tedavi edilen hastalarda bir biyobelirteç ile tersine kardiyak yeniden şekillenme arasında bir ilişki gösterilmiştir.

\section{Kaynaklar}

1. McMurray JJ, Packer M, Desai AS, Gong J, Lefkowitz MP, Rizkala AR, et al. Angiotensin-neprilysin inhibition versus enalapril in heart failure. N Engl J Med 2014;371:993-1004.

2. Wachter R, Senni M, Belohlavek J, Straburzynska-Migaj E, Witte $\mathrm{KK}$, Kobalava Z, et al. Initiation of sacubitril/valsartan in haemodynamically stabilised heart failure patients in hospital or early after discharge: primary results of the randomised TRANSITION study. Eur J Heart Fail 2019;21:998-1007.

3. Fida N, Piña IL. Trends in heart failure hospitalizations. Curr Heart Fail Rep 2012;9:346-53.

4. Velazquez EJ, Morrow DA, DeVore AD, Duffy CI, Ambrosy AP, McCague $\mathrm{K}$, et al. Angiotensin-Neprilysin Inhibition in Acute Decompensated Heart Failure. N Engl J Med 2019;380:539-48.

5. Januzzi JL Jr, Prescott MF, Butler J, Felker GM, Maisel AS, McCague $\mathrm{K}$, et al. Association of Change in N-Terminal Pro-B-Type Natriuretic Peptide Following Initiation of Sacubitril-Valsartan Treatment With Cardiac Structure and Function in Patients With Heart Failure With Reduced Ejection Fraction. JAMA 2019;322:1-11.

6. Desai AS, Solomon SD, Shah AM, Claggett BL, Fang JC, Izzo J, et al. Effect of Sacubitril-Valsartan vs Enalapril on Aortic Stiffness in Patients With Heart Failure and Reduced Ejection Fraction: A Randomized Clinical Trial. JAMA 2019;322:1-10. 